\title{
Canadian Cardiovascular Harmonized National Guidelines Endeavour (C-CHANGE): 2014 update
}

\author{
Sheldon W. Tobe MD, James A. Stone MD PhD, Kimberly M. Walker MPH, Todd Anderson MD, \\ Onil Bhattacharyya MD PhD, Alice Y.Y. Cheng MD, Jean Gregoire MD, Gord Gubitz MD, Mary L'Abbé PhD, \\ David C.W. Lau MD, Lawrence A. Leiter MD, Paul Oh MD, Raj Padwal MD, Luc Poirier MSc, Peter Selby MD, \\ Mark Tremblay PhD, Richard A. Ward MD, Diane Hua MPH, Peter P. Liu MD; for the C-CHANGE Initiative*
}

$\mathrm{I}$ n Canada, the multiple chronic conditions and cardiovascular risk factors of our aging population continue to challenge health care providers and burden health systems. Cardiovascular disease is a major contributor to chronic illness, with four in five Canadians having at least one risk factor for cardiovascular disease and $16 \%$ having three or more risk factors. ${ }^{1}$ In their first-line role, primary care practitioners bear a substantial proportion of the responsibility and patient care load associated with managing risk factors for cardiovascular disease.

Clinical practice guidelines can assist health care practitioners by synthesizing the best available evidence with the use of robust procedures for guideline development, resulting in clear recommendations to guide medical decisionmaking. When this science of medicine intersects with the art of clinical practice, optimal patient care may result. $^{2}$

In 2011, contributors to the Canadian Cardiovascular Harmonized National Guidelines Endeavour (C-CHANGE) created Canada's first harmonized guideline for cardiovascular risk factors. ${ }^{3}$ Using a consensus process, the $2011 \mathrm{C}-\mathrm{CHANGE}$ Guideline Panel accepted 89 key recommendations related to cardiovascular disease from more than 400 existing recommendations sourced from eight different guideline groups. ${ }^{3}$

The 2014 update is a harmonized subset of recommendations from the following guideline groups: Canadian Action Network for the Advancement, Dissemination and Adoption of Practice-informed Tobacco Treatment; ${ }^{4}$ Canadian Association of Cardiac Rehabilitation; ${ }^{5}$ Canadian Cardiovascular Society; ${ }^{6}$ Canadian Diabetes Association; ${ }^{7}$ Canadian Hypertension Education Program $;{ }^{8}$ Canadian Society for Exercise Physiology; ${ }^{9}$ Heart and Stroke Foundation Canadian Stroke Best Practice Recommendations $;{ }^{10}$ and Obesity Canada. ${ }^{11}$ The C-CHANGE Guideline Panel updates its harmonized guideline when the constituent guideline groups release new critically important recommenda- tions or a sufficient number of guideline groups have updated their recommendations.

The 2011 C-CHANGE guideline provided specific recommendations for screening, diagnostic and risk-stratification strategies, treatment targets, health-behaviour recommendations and pharmacologic treatments. Challenges in updating the C-CHANGE guideline include the varying time frames of updates and different grading schemes used by each guideline group.

The opportunity presented by the C-CHANGE process includes both the harmonization of overlapping clinical practice recommendations from each of the member groups and the potential integration of the guideline development process. The primary aim of the $2011 \mathrm{C}$-CHANGE guideline was to develop the harmonization methodology and to produce the first set of harmonized recommendations for prevention and management of cardiovascular disease in primary care. The goal of this second iteration was to establish the integrated review cycle and to demonstrate that guideline groups with harmonized recommendations through C-CHANGE could work collectively to ensure that these recommendations would remain harmonized after the update.

\section{Scope}

In this paper, we highlight the new and important changes in the 2014 C-CHANGE recommendations. The target audience is the primary care community, including primary care physicians,

\section{KEY POINTS}

- This is an update of the 2011 Canadian Cardiovascular Harmonized National Guidelines Endeavour (C-CHANGE) guideline from eight guideline groups.

- Twenty recommendations have been changed or updated and the overall number of recommendations brought down to 74 from 89 .

- The main topic areas of change in this updated version are in lifestyle management, risk-factor screening and risk stratification, and treatment targets for dyslipidemia, particularly for individuals at high risk, such as those with high-risk kidney disease.
Competing interests: See end of article.

This article has been peer reviewed.

\section{The complete list of members of the C-CHANGE Initiative and contributors to C-CHANGE appears at the end of the}

Correspondence to:

Peter Liu,

pliu@ottawaheart.ca

CMAJ 2014. DOI:10.1503 /cmaj.140387 
nurses, nurse practitioners, pharmacists, dietitians and other health care providers, who care for patients with or at risk for vascular disease, such as cardiovascular and cerebrovascular disease. The target population is adults (aged $\geq 18 \mathrm{yr}$ ). We describe the C-CHANGE model of harmonization, the integration of the review cycle, and the implementation and dissemination program.

One of the challenges of practice guidelines is the risk that they will be considered all-encompassing statements with respect to patient care, rather than a collection of evidence-informed recommendations, all or some of which apply to individual patients. The decision to implement a specific recommendation should be tailored to the individual circumstances of each patient. The recommendations contained herein are intended to guide practitioners, but are not meant to replace sound clinical judgment. We recognize that it is the role of clinicians, who best know their patients, to determine whether a recommendation does or does not apply in a certain circumstance; further, we expect that the clinician is able to explain why a recommendation may or may not apply. The recommendations should therefore be considered as a set of sign posts that help health care practitioners achieve best practices for their patients and clients.

\section{Methods}

Recent major updates in the guidelines for hypertension, diabetes, lipids and stroke triggered this second iteration of the C-CHANGE guideline.

\section{Guideline panel composition}

The C-CHANGE Guideline Panel consisted of the lead, chair, co-chair, or a person who held this role or a similar role for each of the individual guideline organizations. Participants had to be a volunteer in their respective organizations, have an academic appointment at a Canadian institution, and be an acknowledged expert in their field based on peer-reviewed publications and reputation. All conflicts of interest were declared beforehand. The C-CHANGE Guideline Panel operates primarily through teleconferences and email with one face-to-face meeting, drawing on funds provided by the Public Health Agency of Canada and Ontario Ministry of Health and Long-term Care.

\section{Guideline development}

The objective of the 2014 C-CHANGE guideline was to update the 2011 version to be consistent with recent updates made by the C-CHANGE partner guideline groups. This meant replacing recommendations that changed in the partner guidelines (Table 1). The revised list of updated recommendations was then reviewed and approved. In a second round of review, recommendations that were deemed redundant were removed after approval by the C-CHANGE Guideline Panel.

An integrated review cycle was developed in collaboration with each of the guideline groups. The review process was initiated in the year following updates to the guidelines from the Canadian Diabetes Association, Canadian Cardiovascular Society (dyslipidemia guideline), and the Canadian Hypertension Education Program. The first version (2011) of the C-CHANGE recommendations was circulated to the leaders of each of the eight guideline groups to identify key upcoming changes in their individual updates. The C-CHANGE Guideline Panel requested that the leadership of each guideline group develop or reconfirm memoranda of understanding among all the groups for a harmonization process for the C-CHANGE recommendations.

Shared working groups were developed to evaluate the evidence (including systematic reviews and grading of evidence), to ensure that shared guidelines had consistent wording for each guideline group, with the goal of being patient-centred and actionable. These summaries are available through the individual guideline groups. For example, in harmonizing a recommendation for blood pressure control in people with diabetes, the scientists who developed the individual recommendations for the diabetes and hypertension groups agreed to accept these recommendations without altering the wording. Another example was seen with the statin recommendation for people with diabetes which is the same in both the diabetes guideline ${ }^{6}$ and dyslipidemia guideline. ${ }^{5}$

Members of the C-CHANGE Guideline Panel worked with the individual guideline groups to verify that they had sufficient methodologic expertise in the critical appraisal process to ensure methodologic rigor and freedom from conflicts of interest in assessing the evidentiary strength of the recommendations. ${ }^{12,13}$ Finally, the C-CHANGE process ensured the wording of the recommendations was consistent with the evidence and could be applied in practice.

Guideline groups may approach the assignment of evidentiary strength differently. Some use the full GRADE (Grading of Recommendations Assessment, Development and Evaluation) system $;{ }^{14}$ others use a modified approach. However, all C-CHANGE recommendations are considered to be "strong" in nature, and C-CHANGE does not make "weak" recommendations. Thus, as an example, the grading scheme of the Canadian 
Table 1 (part 1 of 2): Updated or new recommendations for the 2014 Canadian Cardiovascular Harmonized National Guidelines Endeavour (C-CHANGE) guideline*

Category; population; recommendation

Guideline group

\section{Body habitus}

Target populationt and children

- Measuring BMI is recommended in children aged 2 to $17 \mathrm{yr}$

\section{Diet, sodium and alcohol intake}

Target populationt

- To decrease blood pressure, consider reducing sodium intake toward $2000 \mathrm{mg}$ ( $5 \mathrm{~g}$ of salt) per day.

- All individuals should be encouraged to adopt healthy eating habits to lower their risk of cardiovascular disease: 1)

moderate energy (caloric) intake to achieve and maintain a healthy body weight; 2 ) emphasize a diet rich in vegetables,

fruit, whole-grain cereals and polyunsaturated and monounsaturated oils, including omega-3 fatty acids particularly from

fish; 3 ) avoid trans fats, limit saturated and total fats to $<7 \%$ and $<30 \%$ of daily total energy (caloric) intake, respectively;

4) increase daily fibre intake to $>30 \mathrm{~g} ; 5$ ) limit cholesterol intake to $200 \mathrm{mg}$ daily for individuals with dyslipidemia or at increased risk of cardiovascular disease.

People with diabetes

- People with diabetes should be offered timely diabetes education that is tailored to enhance self-care practices and behaviours.

\section{Risk-factor screening}

\section{Target populationt}

- Screening for diabetes using FPG and/or $A_{1 c}$ should be performed every $3 \mathrm{yr}$ in individuals $\geq 40 \mathrm{yr}$ of age or at high risk

using a risk calculator. More frequent and/or earlier testing with either FPG and/or $A_{1 c}$ or $2 \mathrm{hPG}$ in a 75-g OGTT should be considered in those at very high risk using a risk calculator or in people with additional risk factors for diabetes. These risk factors include the following:

- First-degree relative with type 2 diabetes

- Member of high-risk population (e.g., Aboriginal, African, Asian, Hispanic or South Asian descent)

- History of prediabetes (IGT, IFG or $\mathrm{A}_{1 \mathrm{c}} 6.0 \%-6.4 \%$ )

- History of gestational diabetes mellitus

- History of delivery of a macrosomic infant

- Presence of vascular risk factors (low HDL $[<1.0 \mathrm{mmol} / \mathrm{L}$ in men, $<1.3 \mathrm{mmol} / \mathrm{L}$ in women], high triglyceride levels [ $\geq 1.7 \mathrm{mmol} / \mathrm{L}]$, hypertension, overweight/obesity)

- Presence of associated diseases (polycystic ovary syndrome, acanthosis nigricans, obstructive sleep apnea, psychiatric disorders, HIV infection)

- Use of drugs associated with diabetes (glucocorticoids, atypical antipsychotics, HAART)

- Testing with $2 \mathrm{hPG}$ in a 75-g OGTT should be undertaken in individuals with FPG 6.1-6.9 mmol/L and/or $\mathrm{A}_{1 \mathrm{c}} 6.0 \%-6.4 \%$ to identify individuals with IGT or diabetes.

- Screening of plasma lipids is recommended in men $\geq 40$ and women $\geq 50 \mathrm{yr}$ of age or in postmenopause. Screen lipids at any age for the following: smoking, diabetes, hypertension, overweight, rheumatoid arthritis, systemic lupus erythematosus, psoriatic arthritis, ankylosing spondylitis, inflammatory bowel disease, chronic obstructive pulmonary disease, chronic HIV infection, chronic kidney disease, abdominal aneurysm and erectile dysfunction. Consider screening individuals of First Nations or South Asian ancestry at an earlier age.

People with diabetes

- In people with diabetes, baseline resting ECG should be performed in individuals with any of the following:

- Age $>40$ yr

- Duration of diabetes $>15 \mathrm{yr}$ and age $>30 \mathrm{yr}$

- End-organ damage (micro- or macrovascular)

- Other cardiac risk factors

- Repeat resting ECG every $2 \mathrm{yr}$

\section{Diagnostic strategies}

People with hypertension

- Routine laboratory tests that should be performed for the investigation of all patients with hypertension include the

following: urinalysis; blood chemistry (potassium, sodium and creatinine); fasting blood glucose and/or $A_{1 c}$ fasting serum

total cholesterol, HDL cholesterol, LDL cholesterol and triglyceride levels; and standard 12-lead ECG. 
Table 1 (part 2 of 2): Updated or new recommendations for the 2014 Canadian Cardiovascular Harmonized National Guidelines Endeavour (C-CHANGE) guideline*

Category; population; recommendation

Guideline group

\section{Risk stratification}

Target populationt

- We recommend that a cardiovascular risk assessment, using the "10-year risk" provided by the Framingham model, be completed every 3-5 yr for men aged 40-75 and women aged 50-75 yr. This should be modified (percent risk doubled) when family history of premature cardiovascular disease is positive (i.e., first-degree relative aged $<55 \mathrm{yr}$ for men and $<65 \mathrm{yr}$ for women). A risk assessment might also be completed whenever a patient's expected risk status changes. Younger individuals with at least 1 risk factor for premature cardiovascular disease might also benefit from a risk assessment to motivate them to improve their lifestyle.

- We recommend calculating and discussing a patient's "cardiovascular age" to improve the likelihood that patients will reach lipid targets and that poorly controlled hypertension will be treated.

People with dyslipidemia

- We recommend that high risk be defined in patients who have clinical atherosclerosis, abdominal aortic aneurysm or an adjusted FRS of $\geq 20 \%$. We have also included diabetes of $>15 \mathrm{yr}$ duration and age $>30 \mathrm{yr}$, diabetes with age $>40 \mathrm{yr}$, or the presence of microvascular disease, high-risk kidney disease or high-risk hypertension.

- We recommend that the Intermediate Risk (IR) category include individuals with adjusted FRS $\geq 10 \%$ and $<20 \%$.

\section{Treatment targets}

People with dyslipidemia

- We recommend a target $\mathrm{LDL}$ cholesterol level $\leq 2.0 \mathrm{mmol} / \mathrm{L}$, or $\geq 50 \%$ reduction of $\mathrm{LDL}$ cholesterol for high-risk individuals in whom treatment is initiated. We recommend that apolipoprotein $B \leq 0.80 \mathrm{~g} / \mathrm{L}$ or non-HDL cholesterol $\leq 2.6 \mathrm{mmol} / \mathrm{L}$ be considered as alternative treatment targets for optimal risk reduction.

- In intermediate-risk patients with LDL cholesterol $<3.5 \mathrm{mmol} / \mathrm{L}$, the presence of an apolipoprotein $\mathrm{B} \geq 1.2 \mathrm{~g} / \mathrm{L}$ or non-HDL cholesterol $\geq 4.3 \mathrm{mmol} / \mathrm{L}$ identifies patients at increased risk of cardiovascular disease who might benefit from pharmacotherapy. We recommend a target LDL cholesterol level of $\leq 2.0 \mathrm{mmol} / \mathrm{L}$, or $\mathrm{a} \geq 50 \%$ reduction of $\mathrm{LDL}$ cholesterol for intermediate-risk individuals in whom treatment is initiated. Alternative target variables are apolipoprotein $\mathrm{B} \leq 0.8 \mathrm{~g} / \mathrm{L}$ or non-HDL cholesterol $\leq 2.6 \mathrm{mmol} / \mathrm{L}$.

People with diabetes

- Less stringent $A_{1 c}$ targets ( $7.1 \%-8.5 \%$ in most cases) may be appropriate in patients with type 1 or type 2 diabetes with any of the following:

- Limited life expectancy

- High level of functional dependency

- Extensive coronary artery disease with high risk of ischemic events

- Multiple comorbidities

- History of recurrent severe hypoglycemia

- Hypoglycemia unawareness

- Long-standing diabetes in which it is difficult to achieve an $\mathrm{A}_{1 c} \leq 7.0 \%$ despite effective doses of multiple antihyperglycemic agents, including intensified basal-bolus insulin therapy.

- An intensive lifestyle-intervention program combining dietary modification and increased physical activity may be used to achieve weight loss and improvements in glycemic control and cardiovascular risk factors.

People with hypertension

- In very elderly patients (age $\geq 80 \mathrm{yr}$ ) who do not have diabetes or target organ damage, the systolic blood pressure threshold for initiating drug therapy is $\geq 160 \mathrm{~mm} \mathrm{Hg}$ and the systolic blood pressure target is $<150 \mathrm{~mm} \mathrm{Hg}$.

\section{Pharmacologic and/or procedural therapy}

People with diabetes

- Statin therapy should be used to reduce cardiovascular risk in adults with type 1 or type 2 diabetes with any of the

following: a) clinical macrovascular disease; b) age $\geq 40 \mathrm{yr}$; c) age $<40 \mathrm{yr}$ and one of the following: diabetes duration $>15 \mathrm{yr}$ and age $>30 \mathrm{yr}$ or microvascular complications.

- Angiotensin-converting enzyme inhibitor or angiotensin receptor blocker, at doses that have demonstrated vascular protection, should be used to reduce cardiovascular risk in adults with type 1 or type 2 diabetes with any of the following:

a) clinical macrovascular disease; b) age $\geq 55 \mathrm{yr}$; c) age $<55 \mathrm{yr}$ and microvascular complications.

Note: $2 \mathrm{hPG}=2$ - $\mathrm{h}$ plasma glucose test, $\mathrm{A}_{1 \mathrm{c}}=$ glycated hemoglobin, BMI = body mass index, CCS = Canadian Cardiovascular Society, CDA = Canadian Diabetes Association, CHEP $=$ Canadian Hypertension Education Program, ECG = electrocardiogram, FPG $=$ fasting plasma glucose, FRS $=$ Framingham Risk Score, HAART = highly active antiretroviral therapy, $\mathrm{HDL}=$ high-density lipoprotein, IFG = impaired fasting glucose, IGT = impaired glucose tolerance, LDL = low-density lipoprotein, OGTT = oral glucose tolerance test.

*The entire list of recommendations is available in Appendix 1, at www.cmaj.ca/lookup/suppl/doi:10.1503/cmaj.140387/-/DC1.

tThe target population is adults (aged $\geq 18 \mathrm{yr}$ ). 
Hypertension Education Program refers only to the quality of evidence and not to the relative strength of the recommendation, because all are considered strong recommendations. ${ }^{15}$

Additionally, guideline groups develop guidelines with a "strong intent." A recommendation with strong intent is defined by the National Institute for Health and Care Excellence (formerly the National Institute for Health and Clinical Excellence; NICE), as one that most people would follow if they had a good working knowledge of the issues. ${ }^{16}$ Given the NICE criterion, a recommendation based on the consensus of a group of national experts in the area could be considered of strong intent, even though the evidence base was weak (e.g., absence of randomized controlled trials [RCTs]). Efforts are made to limit the number of these consensus recommendations, because of the risk of introducing bias or agendas.

The evidence required for specific types of recommendations varies. For drug therapy recommendations, a strong evidentiary base is required with RCTs with measurable outcomes and excellent internal validity. Health behaviour recommendations are permitted to be based on RCTs with surrogate outcomes (i.e., blood glucose or blood pressure levels). Diagnostic recommendations are based on prospective studies demonstrating that the diagnostic test is predictive of measurable outcomes. A cost analysis was not included because we believe that the assumptions required are best made by the individual jurisdictions implementing the recommendations.

\section{Recommendations}

The updated C-CHANGE guideline has been streamlined to include 74 recommendations, down from 89 . These include 20 recommendations that are new or have been updated for 2014 and primarily reflect the updated Canadian Diabetes Association guideline and the Canadian Cardiovascular Society's dyslipidemia guideline. The updated recommendations are found in Table 1 and Appendix 1 (available at www.cmaj.ca /lookup/suppl/doi:10.1503/cmaj.140387/-/DC1).

The implementability (e.g., clarity, simplicity and format) of the recommendations remains an ongoing process, with a target of applying it to all the C-CHANGE recommendations by the next cycle. ${ }^{17}$ Details of the recommendations are found in Appendix 1, including the associated guideline group, evidence supporting each recommendation and references.

The Appraisal of Guidelines for Research and Evaluation (AGREE II) tool is used to assess the quality and reporting of a set of practice guide- lines. ${ }^{12}$ Appendix 2 (available at www.cmaj.ca /lookup/suppl/doi:10.1503/cmaj.140387/-/DC1) provides an AGREE II assessment of this guideline. The assessment should help guideline users evaluate the C-CHANGE guideline and the C-CHANGE process itself to evolve and to continue to improve.

\section{Implementation and evaluation}

Guideline dissemination and implementation has the potential to integrate best available evidence into practice, to reduce inconsistencies, to minimize harm, to facilitate interdisciplinary collaboration between specialists and generalists and interprofessional collaboration between physicians and other members of the health care team, and to ultimately improve overall quality of care. ${ }^{18-20}$ However, there is inconsistent evidence to support which implementation strategies are most likely to facilitate the use of guidelines in practice. ${ }^{19,21,22}$ Multiple strategies seem to hold the most promise. ${ }^{23}$

Implementation strategies developed by the C-CHANGE Initiative can be found in Box 1 . The C-CHANGE process facilitates the sharing of implementation strategies among the participating guideline groups. More information on implementation is found in Appendix 3 (available at www.cmaj.ca/lookup/suppl/doi:10.1503/cmaj $.140387 / / / \mathrm{DC} 1)$.

C-CHANGE collaborates with various provinces and the eight guideline partners to create C-CHANGE practice tools and programs that ensure the principles of harmonization are

\section{Box 1: Tools and resources for providers and patients}

C-CHANGE resources

- Clinical resource centre for clinicians: www.c-changecrc.ca

- Patient resource centre: www.cchangeinme.com

- Guidelines app (will be available from the App Store)

Participating guideline groups

- Canadian Action Network for the Advancement, Dissemination and Adoption of Practice-informed Tobacco Treatment: www .nicotinedependenceclinic.com/English/CANADAPTT/Pages/Home.aspx

- Canadian Association of Cardiac Rehabilitation: www.cacpr.ca

- Canadian Cardiovascular Society (dyslipidemia guideline): www .ccsguidelineprograms.ca/index.php?option=com_content\&view=article \&id $=88$ \& 1 temid $=83$

- Canadian Diabetes Association: http://guidelines.diabetes.ca/app

- Canadian Hypertension Education Program: www.hypertension.ca

- Canadian Society for Exercise Physiology: http://csep.ca/english/view .asp? $\mathrm{x}=804$

- Heart and Stroke Foundation Canadian Stroke (Best Practices): www .strokebestpractices.ca/

- Obesity Canada: www.obesitynetwork.ca 
upheld. These principles are as follows: that the tools and programs are consistent and not fragmented, that they are of high quality and are measurable, that there is fidelity with the C-CHANGE clinical recommendations and decision support process, and that they are aligned provincially and nationally.

\section{Conclusion}

Ongoing efforts by the C-CHANGE Initiative have resulted in a set of recommendations that provide a single authoritative source for recommendations for most primary care management for vascular disease. This was only possible with the direct participation and partnership with each individual guideline group. Between now and the next cycle, which will again be chosen strategically to coincide with major changes in the component recommendations, efforts will focus on harmonizing implementation processes with the individual guideline groups. The C-CHANGE Initiative will undertake to work with ministries of health and clinical service providers to integrate the C-CHANGE recommendations seamlessly into electronic medical record systems.

The entire list of recommendations is available in Appendix 1.

\section{References}

1. McAlister FA, Robitaille C, Gillespie C, et al. The impact of cardiovascular risk factor profiles on blood pressure control rates in adults from Canada and the United States. Can J Cardiol 2013;29:598-605

2. Battista RN, Hodge MJ. Clinical practice guidelines: between science and art. CMAJ 1993;148:385.

3. Tobe SW, Stone JA, Brouwers M, et al. Harmonization of guidelines for the prevention and treatment of cardiovascular disease: the C-CHANGE Initiative. CMAJ 2011;183:E1135-50.

4. CAN-ADAPTT. Canadian smoking cessation clinical practice guideline. Toronto: Canadian Action Network for the Advancement, Dissemination and Adoption of Practice-informed Tobacco Treatment; 2011

5. Stone JA, Arthur HM, Suskin N. Canadian guidelines for cardiac rehabilitation and cardiovascular disease. Prevention: translating knowledge into action. Winnipeg: Canadian Association of Cardiac Rehabilitation; 2009.

6. Anderson TJ, Gregoire J, Hegele RA, et al. 2012 update of the Canadian Cardiovascular Society guidelines for the diagnosis and treatment of dyslipidemia for the prevention of cardiovascular disease in the adult. Can J Cardiol 2013;29:151-67.

7. Cheng AY, Lau DC. The Canadian Diabetes Association 2013 clinical practice guidelines - raising the bar and setting higher standards! Can J Diabetes 2013;37:137-8.

8. Hackam DG, Quinn RR, Ravani P, et al. The 2013 Canadian Hypertension Education Program (CHEP) recommendations for blood pressure measurement, diagnosis, assessment of risk, prevention, and treatment of hypertension. Can J Cardiol 2013;29: 528-42.

9. Tremblay MS, Warburton DE, Janssen I, et al. New Canadian physical activity guidelines. Appl Physiol Nutr Metab 2011;36: 36-46.

10. Lindsay MP, Gubitz G, Bayley M, et al. Canadian stroke best practice recommendations: overview and methodology. Ottawa: Canadian Heart and Stroke Foundation; 2013.

11. Lau DC, Douketis JD, Morrison KM, et al. 2006 Canadian clinical practice guidelines on the management and prevention of obesity in adults and children [summary]. CMAJ 2007;176: S1-13.
12. Brouwers MC, Kho MEBP, Browman GP, et al. AGREE II: advancing guideline development, reporting and evaluation in health care. CMAJ 2010;182:E839-42.

13. Ransohoff DF, Pignone M, Sox HC. How to decide whether a clinical practice guideline is trustworthy. JAMA 2013;309:139-40.

14. Guyatt G, Gutterman D, Baumann MH, et al. Grading strength of recommendations and quality of evidence in clinical guidelines: report from an American college of chest physicians task force. Chest 2006;129:174-81.

15. McAlister FA. van Diepen S, Padwal RS, et al. How evidencebased are the recommendations in evidence-based guidelines? PLoS Med 2007;4:e250.

16. The guidelines manual. London (UK): National Institute for Health and Clinical Excellence (NICE); 2009.

17. Kastner M, Estey E, Bhattacharyya O. Better guidelines for better care: enhancing the implementability of clinical practice guidelines. Expert Rev Pharmacoecon Outcomes Res 2011;11: 315-24.

18. Vernooij RW, Sanabria AJ, Solà I, et al. Guidance for updating clinical practice guidelines: a systematic review of methodological handbooks. Implement Sci 2014;9:3.

19. Grimshaw JM, Thomas RE, Maclennan G, et al. Effectiveness and efficiency of guideline dissemination and implementation strategies. Health Technol Assess 2004;8:iii-iv.

20. Woolf SH, Grol R, Hutchinson A, et al. Clinical guidelines: potential benefits, limitations, and harms of clinical guidelines. BMJ 1999;318:527-30.

21. Gagliardi AR, Brouwers MC, Palda VA, et al. How can we improve guideline use? A conceptual framework of implementability. Implement Sci 2011;6:26.

22. Grimshaw J, Eccles M, Tetroe J. Implementing clinical guidelines: current evidence and future implications. J Contin Educ Health Prof 2004;24(Suppl 1):S31-7.

23. Francke AL, Smit MC, de Veer AJ, et al. Factors influencing the implementation of clinical guidelines for health care professionals: a systematic meta-review. BMC Med Inform Decis Mak 2008;8:38.

Competing interests: Sheldon Tobe has received research funding from Eli Lilly and Company, AstraZeneca, AbbVie and Bayer. James Stone has received funding from Amgen, Forest Laboratories, Merck and Sanofi. Todd Anderson declares research study involvement with Merck and Amgen. Onil Bhattacharyya has received funding from GlaxoSmithKline, Merck, Merck Serono and Novartis. Alice Cheng declares personal fees from AstraZeneca, Boehringer Ingelheim, Eli Lilly and Company, Janssen, Merck, Novo Nordisk, Sanofi, Servier, Valeant Pharmaceuticals International, Abbott and Takeda Pharmaceutical Company. Gord Gubitz has received funds from Pfizer-Bristol-Myers Squibb, Bayer and Boehringer Ingelheim, and is a member of the steering committee for the Heart and Stroke Foundation of Canada Stroke Best Practices. David Lau declares receiving funds from AstraZeneca, Boehringer Ingelheim, Bristol-Myers Squibb, Eli Lilly and Company, Janssen, Merck, Novo Nordisk, Roche, Sanofi and Valeant Pharmaceuticals International. Lawrence Leiter declares grants or personal fees from AstraZeneca, Boehringer Ingelheim, Bristol-Myers Squibb, Eli Lilly and Company, GlaxoSmithKline, Janssen, Merck, Novartis, Novo Nordisk, Roche, Sanofi, Servier, Takeda Pharmaceutical Company and Amgen. Raj Padwal has received funds from Forest Laboratories, Medtronic, Novo Nordisk, CVRx, Valencia, Abbott, Servier and Merck. Peter Selby has received funds from Pfizer and AbbVie. No competing interests were declared by Kimberly Walker, Onil Bhattacharyya, Jean Gregoire, Gord Gubitz, Mary L'Abbé, Paul Oh, Luc Poirier, Mark Tremblay, Richard Ward and Diane Hua.

Affiliations: Division of Nephrology (Tobe), Sunnybrook Health Sciences Centre, University of Toronto, Toronto, Ont.; Libin Cardiovascular Institute of Alberta (Stone), University of Calgary, Cardiac Wellness Institute of Calgary, Calgary, Alta.; University Health Network, Toronto General Hospital (Walker), Toronto, Ont.; Libin Cardiovascular Institute of Alberta (Anderson), University of Calgary Calgary Alta.; Women's College Hospital (Bhattacharrya), University of Toronto, Toronto, Ont.; Division of Endocrinology and Metabolism (Cheng), St. Michael's Hospital, University of Toronto, Toronto, Ont.; Institut de cardiologie de Montréal 
(Gregoire), Université de Montréal, Montréal, Que.; Division of Neurology (Gubitz), Dalhousie University, Halifax, NS.; Department of Nutritional Sciences (L'Abbé), University of Toronto, Toronto, Ont.; Division of Endocrinology and Metabolism (Lau), Julia McFarlane Diabetes Research Centre, Libin Cardiovascular Institute of Alberta, University of Calgary, Calgary, Alta.; Keenan Research Centre (Leiter), Li Ka Shing Knowledge Institute, St. Michael's Hospital, University of Toronto, Toronto, Ont.; Toronto Rehabilitation Institute (Oh), University Health Network, University of Toronto, Toronto, Ont.; Departments of Clinical Epidemiology and Pharmacology, and Division of General Internal Medicine (Padwal), University of Alberta, Edmonton, Alta.; Département de pharmacie, Centre Hospitalier Universitaire de Québec et Faculté de Pharmacie, Université Laval, Québec, Que.; Centre for Addiction and Mental Health, the Departments of Family and Community Medicine, and Psychiatry, and Dalla Lana School of Public Health (Selby), University of Toronto, Toronto, Ont.; The Children's Hospital of Eastern Ontario Research Institute (Tremblay), Ottawa, Ont.; the Department of Family Medicine (Ward), University of Calgary, Alta.; Sunnybrook Research Institute (Hua) Toronto, Ont.; University of Ottawa Heart Institute (Liu), Ottawa, Ont.

Contributors: Sheldon Tobe, James Stone and Peter Liu wrote the first and subsequent versions of the manuscript. Kimberly Walker wrote the "Implementation and evaluation" section and parts of the "Methods" section. Todd Anderson, Onil Bhattacharyya, Alice Cheng, Jean Gregoire, Gordon Gubitz, Mary L'Abbé, David Lau, Lawrence Leiter, Paul Oh, Raj Padwal, Luc Poirier, Peter Selby, Mark Tremblay and Richard Ward are members of the C-CHANGE Guideline
Panel and developed the 2014 C-CHANGE guideline, and reviewed and made substantive contributions to the manuscript. Diane Hua developed the AGREE II assessment table (Appendix 2), and reviewed the manuscript. All of the authors approved the final version submitted for publication and agree to act as guarantors of the work.

Funding: Funding for the development of the 2014 C-CHANGE guideline was provided by the Ontario Ministry of Health and Long-term Care. The C-CHANGE implementation activities were funded by the Public Health Agency of Canada (no. 6464-15-201-8041132) and the Ontario Ministry of Health and Long-term Care (grant no. 06668 and 0669). The funders did not have a direct influence on the process, the contents of the recommendations or the preparation of the manuscript.

C-CHANGE Initiative: James Stone, Sheldon Tobe, Peter Liu, Diane Hua and Kimberly Walker (C-CHANGE executive). The C-CHANGE executive acknowledges the insightful advice, wisdom and enthusiastic support of the following people who have contributed to the C-CHANGE process, the implementation and/or evaluation, and the 2014 update: Melissa Brouwers PhD; Norman R.C. Campbell MD; David Dannenbaum MD; Martin Dawes MD PhD; Denis Drouin MD; Ross Feldman MD; Jacques Genest MD; Steven Goluboff MD; Steven Grover MD MPA; John Hickey MD; Tim Hutchinson MPA; Janusz Kaczorowski PhD; Karim Keshavjee MD MBA; Kori Kingsbury MPA; Karen Mann PhD; Andrew Pipe MD; Christina Sit MSc; Sol Stern MD; Guy Tremblay MD; Karen Tu MD MSc; Darren Warburton MSc $\mathrm{PhD}$; Richard A. Ward MD; Vincent Woo MD; George Yeung MSc PhD

\title{
How you can get involved in the CMA!
}

The CMA is committed to providing leadership for physicians and promoting the highest standard of health and health care for Canadians. To strengthen the association and be truly representative of all Canadian physicians the CMA needs to hear from members interested in serving in elected positions and on appointed committees and advisory groups. The CMA structure comprises both governing bodies and advisory bodies either elected by General Council or appointed by the CMA Board of Directors. The Board of Directors - elected by General Council - has provincial/territorial, resident and student representation, is responsible for the overall operation of the CMA and reports to General Council on issues of governance.

CMA committees advise the Board of Directors and make recommendations on specific issues of concern to physicians and the public. Five core committees mainly consist of regional, resident and student representation while other statutory and special committees and task forces consist of individuals with interest and expertise in subject-specific fields. Positions on one or more of these committees may become available in the coming year.

For further information on how you can get involved please go to https://www.cma.ca/en/Pages/get-involved-in-cma.aspx, or contact

\author{
Cherise Araujo \\ Corporate and Governance Services \\ Canadian Medical Association \\ 1867 Alta Vista Drive, Ottawa ON K1G 5 W8 \\ Fax 613 526-7570, Tel 800 663-7336 x1949 \\ cherise.araujo@cma.ca
}

By getting involved, you will have an opportunity to make a difference.

We hope to hear from you!

ASSOCIATION
MÉDICALE
CANADIENNE

